\title{
HELICOBACTER PYLORI CO-INFECTED WITH COMMON INTESTINAL PROTOZOA IN GASTROINTESTINAL SYMPTOMATIC PATIENTS
}

By

MARWA M. I. GHALLAB ${ }^{1}$ AND SALWA M. MORSY2,3*

Department of Medical Parasitology, Faculty of Medicine, Kafrelsheikh University ${ }^{1}$, and Department of Medical Parasitology, Faculty of Medicine, Cairo University ${ }^{2^{*}}$ and Faculty of Medicine, Modern University for Technology and Information ${ }^{3}$, Cairo, Egypt ( ${ }^{*}$ Correspondence: Smmorsy@kasralainy.edu.eg)

\section{Abstract}

The zoonotic intestinal protozoan parasites and Helicobacter pylori) are worldwide distributed human pathogens. This study evaluated the co-infection between H. pylori and the commonest intestinal protozoan parasites. A total of 240 stool samples were collected over one year from patients attending outpatients' clinics of Kafrelsheikh University Hospitals, after verbal consent for participation. Samples were subjected to microscopic examination directly before and after formol ether concentration. Samples were examined using merthiolate iodine formalin (MIF) direct smears to detect $G$. intestinelis and permanent modified trichrome and modified acid-fast cold kinyoun's stained smears to detect E. histolytica/dispar and Cryptosporidium spp. respectively. Screening with immune-chromatographic test (ICT) detected $H$. pylori infection. The results showed that $H$. pylori were in 160/240 (66.7\%). Univariate analysis showed significance association between $H$. pylori and protozoan causing diarrhea $(P=0.015)$. These protozoan parasites were with $G$. intestinalis $((\mathrm{P}=0.002)$, E. histolytica/dispar $(\mathrm{P}=0.041)$, Cryptosporidium parvum $(\mathrm{P}=0.018)$ and Blastocystis hominis $(\mathrm{P}=0.040)$.

Key words: Patients, Heliobacter pylori, Intestinal protozoan parasites

\section{Introduction}

Among the commonest prevalent diseases worldwide were intestinal parasitosis (Jayalakshmi and Dharanidevi, 2016). These infections are a serious public health infection causing physical and mental health problems (Tandukar et al, 2013). These infections included intestinal protozoa; Giardia lamblia and Cryptosporidium spp. that proved to have a serious impact on children and Entamoeba histolytica with a higher morbidity in all aged patients (Mortimer and Chadee, 2010).

Helicobacter pylori (H. pylori) are gramnegative bacteria that colonize human stomach and considered the most common chronic human bacterial infection worldwide infecting more than $50 \%$ of the population in both developed and developing countries (Dane and Gurbuz, 2016) with much higher prevalence in developing countries (Eldash et al, 2013). H. pylori colonize the stomach's mucus layer inducing chronic gastric inflammation (Konturek, 2003). It is considered to be a major cause of gastric and duodenal ulcers and a risk factor for the gastric malignancies (Mutaz and Carmen, 2015). They produced some enzymes that could cause destructive effect on the epithelial lining of the stomach and more importantly, active urease enzyme (Cameron et al, 2001).

Urease produced by $H$. pylori can transform the urea of stomach wall to ammonia resulting in the increment of gastric environment's pH (Isaeva and Efimova, 2010). Acidity of the stomach is considered an important barrier of the innate immune system that protect against invasion by pathogens, therefore the diminished acidity will give pathogens the opportunity to break this barrier and go across it invading the gastric mucosa (Kazemian et al, 2016). H. pylori infection shared intestinal Parasites in multiple clinical presentations as diarrhea, dysentery, vomiting, lack of appetite and abdominal distention (Ahmed et al, 2018). H. pylori can be identified by using simple techniques (Guerrant et al, 2011) and Copro immunoassays as immune-chromatographic test (ICT) (Abd Elbagi et al, 2019).

This study aimed to evaluate co-infection prevalence of Heliobacter pylori in sympto- 
matic patients with intestinal protozoa causing diarrhea Giardia intestinalis, Entamaeba histolytica/dispar, Cryptosporidium pa-rvum and Blastocystis hominis among the outpatients of Kafrelsheikh University Hospitals.

\section{Materials and Methods}

Study design: A cross sectional study was conducted over 240 patients of both sexes, aged from 1 to 45 years old attending Outpatient Clinics of Kafrelsheikh University Hospitals all over the year 2019, suffering from gastrointestinal manifestations including abdominal pain, nausea, vomiting, diarrhea, abdominal bloating. Patients on anti-diarrheal medications were excluded. Patients included were divided into 3 age groups; G1:115 years, G2:16-30 \& G3: 31-45 years. A single fecal sample was obtained from each patient after verbal consent and recording demographic, clinical and environmental data by using a designed questionnaire.

All samples were microscopically examined to detect protozoa by wet mount smear \& formol ether concentration. Merthiolate iodine formalin (MIF) direct smear were used for G. intestinelis (El-Taweel and Abou Holw, 2008), modified acid fast cold Kinyoun's stain for C. parvum (El-Shazly et al, 2006). and modified Trichrome (Garcia, 2007) for E. histolytica/dispar

H. pylori copro-antigen was detected using ICT (ACON Laboratories Inc., San Diego, USA) after the manufacturer's instructions.
Statistical analysis: Data were tabulated and analyzed by using the package SPSS version 21 (Chicago, IL, USA) for the statistical analysis. Data were described using frequency and percentage with $P<0.05$ was considered significant.

\section{Results}

In the present study, $H$. pylori were detected in $160 / 240(66.7 \%)$ samples. Infection in G1, G2 \& G3 was $55 \%, 25 \%$ \& $20 \%$ in respectively among $54.4 \%$ males \& $45.6 \%$ females, without significance between age nor sex. As to gastrointestinal pictures, 128/160 (80\%) H. pylori patients were presented by abdominal pain, 72(45\%) nausea, 64 (40\%) vomiting and $96(60 \%)$ diarrhea. Bloating was $96(60 \%)$ patients, significant association $(\mathrm{P}=0.015)$ between $H$. pylori infection and diarrhea only. Of $H$. pylori positive patients, $134(83.8 \%)$ were co-infected with protozoa; 31 (19.3\%), 27 (16.8\%), 32 (20\%) and $68(42.5 \%)$ with G. intestinali, E. histolytica, C. parvum \& B. honinis respectively. Significant association was between $H$. pylo$r i$ and $G$. intestinali $(\mathrm{P}=0.002), E$. histolytica $(\mathrm{P}=0.041), C$. parvum $(\mathrm{P}=0.018) \& B$. hominis $(\mathrm{P}=0.040)$. Also, 45/80 (56.2\%) patients were $H$. pylori free but with $G$. intestinalis 4 (5\%), E. histolytica/dispar 22 (27.5\%), C. parvum 7 (8.7\%) and B. honinis $24(30 \%)$.

The details were given in tables $(1 \& 2)$.

\begin{tabular}{|c|c|c|c|c|}
\hline \multicolumn{2}{|c|}{ Variants } & Positive cases $(n=160)$ & Negative cases $(n=80)$ & $\mathrm{P}$ value \\
\hline \multirow[t]{3}{*}{ Age } & G1 (1-15 years) & $88(55 \%)$ & $44(55 \%)$ & \multirow[t]{3}{*}{1.000} \\
\hline & G2 (16-30 years) & $41(25.7 \%)$ & $20(25 \%)$ & \\
\hline & G3 (31-45 years) & $31(19.3 \%)$ & $16(20 \%)$ & \\
\hline \multirow[t]{2}{*}{ Sex } & Male & $87(54.4 \%)$ & $44(55 \%)$ & \multirow[t]{2}{*}{0.519} \\
\hline & Female & $73(45.6 \%)$ & $36(45 \%)$ & \\
\hline \multirow{5}{*}{$\begin{array}{l}\text { Associated } \\
\text { GIT symp- } \\
\text { toms }\end{array}$} & Abdominal pain & $128(80 \%)$ & $60(75 \%)$ & 0.234 \\
\hline & Nausea & $72(45 \%)$ & $40(50 \%)$ & 0.276 \\
\hline & Vomiting & $64(40 \%)$ & $28(35 \%)$ & 0.272 \\
\hline & Diarrhea & $96(60 \%)$ & $60(75 \%)$ & 0.015 \\
\hline & Bloating & $96(60 \%)$ & $44(55 \%)$ & 0.273 \\
\hline \multicolumn{2}{|c|}{ Over all percentage } & 66.7 & 33.3 & \\
\hline
\end{tabular}

Table 2: Co-infection between $H$. pylori and intestinal protozoa significance

\begin{tabular}{|l|c|c|c|}
\hline \multicolumn{1}{|c|}{ Associated Variants } & +ve $(\mathrm{n}=160)(66.7 \%)$ & $-\mathrm{ve}(\mathrm{n}=80)(33.3 \%)$ & $\mathrm{P}$ value \\
\hline Giardia intestinalis & $31(19.3 \%)$ & $4(5 \%)$ & 0.002 \\
\hline Entamoeba histolytica/dispar & $27(16.8 \%)$ & $22(27.5 \%)$ & 0.041 \\
\hline Cryptosporidium parvum & $32(20 \%)$ & $7(8.7 \%)$ & 0.018 \\
\hline Blastocystis hominis & $68(42.5 \%)$ & $24(30 \%)$ & 0.040 \\
\hline Free from intestinal protozoa & $26(16.2 \%)$ & $35(43.8 \%)$ & \\
\hline
\end{tabular}




\section{Discussion}

Generally speaking, H. pylori is one the principle cause of chronic gastric inflammation, peptic and duodenal ulcers, nonulcerative dyspepsia, gastric carcinoma and gastric mucosa associated lymphoid tissue lymphoma (Khalifa et al, 2010). The reduction of stomach acidity caused by urease activity of $H$. pylori was as a risk factor for parasitic infections (Sanad et al, 1996).

This study showed higher prevalence of $H$. pylori among 1-15 years age group followed by $16-30$ years age group was $55 \% \& 25 \%$ respectively. This agreed with Abd Elbagi et al. (2019) who found that high prevalence of H. pylori was in $1-15$ years age group $(40 \%)$ and second high prevalence was in ages older than 16-30 years (38\%), but disagreed with Fadul et al. (2016) who found a high rate $(50 \%)$ in patients $>66$ years old.

The present results showed prevalence of H. pylori in males and females was $54.4 \%$ \& $45.6 \%$ respectively without s significant difference. This agreed with El-Massry et al. (2003) and Kazemian et al. (2014). But, this disagreed with El-Badry et al. (2017) who reported that sex was significantly in $H$. pylori co-infected with Giardia. Also, Seid et al. (2018) who reported significant association between the male sex and $H$. pylori-coinfected with intestinal parasites

In the present study, gastrointestinal manifestations were abdominal pain, nausea, vomiting, diarrhea and bloating with significant association between $H$. pylori and diarrhea $(\mathrm{P}=0.015)$. This agreed with CastilloMontoyaa et al. (2017) who reported significant association between $H$. pylori and protozoa causing diarrhea $(\mathrm{P}=0.0389)$.

The prevalence of $\mathrm{G}$. intestinalis $(19.3 \%)$ was lower than that reported by Kazemian et al. (2016) and Isaeva et al. (2010) who showed that $G$. intestinalis co-infected with $H$. pylori was $42 \%$ \& $100 \%$ respectively. Also, Moreira et al. (2005) and Ankarklev et al. (2012) reported significant relation between $H$. pylori and G. intestinalis.

The present rate of E. histolytica/dispar
$(16.8 \%)$ was higher than that found by Abd Elbagi et al. (2019) who reported $12 \%$ for $E$. histolytica/dispar among $H$. pylori patients but lower than $(21.5 \%)$ reported by either Torres et al. (2003) or (55.5\%) reported by Ahmed et al. (2018).

In the present study, B. hominis (42.5\%) was lower than $67.2 \%$ reported by Nghaimesh et al. (2018). Concerning C. parvum (20\%), Ibrahim et al. (2019) found a rate of $5.3 \%$ with a significant statistical association between $H$. pylori infection and Cryptosporidium spp. $(\mathrm{p}=0.02)$.

\section{Conclusion}

There was high prevalence $(66.7 \%)$ of $H$. pylori in Kafrelsheikh. Also, G. intestinalis, E. histolytica/dispar, C. parvum and B. hominis were prevalent in $H$. pylori patients than $H$. pylori free ones with significant differences. Undoubtedly, treating of the gastrointestinal parasites is a must when treating $H$. pylori

\section{References}

Abd Elbagi, Y, Abd Alla, AB, Saad, MBE, 2019: The relationship between Helicobacter pylori infection and intestinal parasites in individuals from Khartoum state, Sudan, F1000 Res. 8:2094.

Ahmed, AK, Kamal, AM, El-Saghier, NM, Hassan, EE, Osman, HA et al, 2018: Association between Entamoeba histolytica/dispar and Helicobacter pylori infections in patients with gastrointestinal complaints, J. Egypt. Soc. Parasitol. 48, 1:31-4

Ankarklev J, Hestvik E, Lebbad M, Lindh J, Kaddu-Mulindwa DH,O. et al, 2012: Common coinfections of Giardia intestinalis and Helicobacter pylori in non-symptomatic Ugandan children. PLoS Negl. Trop. Dis. 6, 8:e1780.

Cameron, I, Marion, R, Billy, B, Brendan, D, 2001: Is Helicobacter pylori infection in childhood a risk factor for gastric cancer? Pediatr. 107, 2:373-80.

Castillo-Montoyaa, V, Ruiz-Bustos, E, Valencia-Juillerat, ME, Álvarez-Hernándezc, G, Sotelo-Cruzc, N, 2017: Detection of Helicobacter pylori in children and adolescents using the monoclonal coproantigen immunoassay and its association with gastrointestinal diseases. Cirugía Y Cirujanos 85, 1:27-33 
Dane, A, Gurbuz, T, 2016: Clinical comparative study of the effects of Helicobacter pylori colonization on oral health in children. Pakist. J. Med. Sci. 32, 4:969-73.

El-badry AA, Ghieth M, Ahmed DA, Ismail, MA, 2017: Giardia intestinalis and helicobacter pylori co-infection: Estimated risks and predictive factors in Egypt, J. Egypt. Soc. Parasitol. 47, 1:19-24.

Eldash, HH, Bekhit, OE, Algameel, AA, 2013: Impact of Helicobacter pylori-giardiasis co-infection on children with recurrent abdominal pain. J. Egypt. Soc. Parasitol. 43, 2:509-16.

El-Massry, AM, Thabet, TM, Kassem, AN, Badr El-din, S, 2003: Helicobacter pylori infection among school children in Alexandria: Possible association with intestinal parasitic infections. Bull. High Inst. Pub. Hlth. 33, 1:141-56.

El-Shazly, AM, Awad, SE, Sultan, et al, 2006: Intestinal parasites in Dakahlia Governorate, with different techniques in diagnosing protozoa, J. Egypt. Soc. Parasitol. 36, 3:1023-34.

El-Taweel HA, Abou Holw SA, 2009: Use of a non-mercury containing fixative for diagnosis of giardiasis. J. Egypt. Soc. Parasitol. 38, 1:65-72.

Fadul N, Ahmed M, Elamin T, et al, 2016: Prevalence Rate Of Giardia lamblia/Helicobacter pylori co-infections in Khartoum State, Sudan, Inter. J. Sci. Technol. Res. 5, 3:181-90.

Garcia, LS, 2007: Diagnostic Medical Parasito$\operatorname{logy}, 5^{\text {th }}$ edition, ASM press, Washington DC.

Guerrant, RL, Walker, DH, Weller, PF, 2011: Tropical Infectious Diseases: Principles, Pathogens and Practice, $3^{\text {rd }}$ edition, Elsevier Inc.

Ibrahim A, Ali YBM, Abdel-Aziz A, El-Badry AA, 2019: Helicobacter pylori and enteric parasites co-infection among diarrheic and non-diarrheic Egyptian children: Seasonality, estimated risks, and predictive factors. J. Parasit. Dis. 43, 2:198-208.

Isaeva, GSh, Efimova, NG, 2010: Gastrointestinal giardiasis associated with Helicobacter pylori. Eksp. Klin. Gastroenterol. 6:30-4.

Jayalakshmi, S, Dharanidevi, S, 2016: The prevalence of intestinal parasitic infections in a tertiary care hospital in southern India: A retrospective study. Int. J. Curr. Microbiol. App. Sci. 5, 10:718-23.

Kazemian, H, Shavalipour, A, Mohebi, R, et al, 2014: Estimation of the parasitic infection prevalence in children with Helicobacter pylori infection in Ilam City (2012-2013). Arch. Pediatr. Infect. Dis. 2, 3: e15294.

Kazemian, H, Heidari, H, Yamchi, JK, Shavalipour, A, Ghafourian, S, et al, 2016: Relationship between Helicobacter pylori infection and parasitic infection in patients in Ilam City. Infect. Epidemiol. Med. 2, 2:15-7.

Khalifa, MM, Sharaf, RR, Aziz, RK, 2010: Helicobacter pylori: A poor man's gut pathogen. Gut Pathol. 2, 1:2-4.

Kim, N, 2016: Helicobacter pylori, Edited by N. Kim, Springer Nature.

Konturek, JW, 2003: Discovery by Jaworski of Helicobacter pylori and its pathogenetic role in peptic ulcer, gastritis and gastric cancer. J. Physiol. Pharmacol. 54, 3:23-41.

Moreira, ED, Nassri, VB, Santos, et al, 2005: Association of Helicobacter pylori infection and Giardiasis: Results from a study of surrogate markers for fecal exposure among Children, Wld. J. Gastroenterol. 11, 18:2759-63.

Mortimer, L, Chadee, K, 2010: The immunopathogenesis of Entamoeba histolytica. Exp. Parasitol. 126, 3:366-80.

Mutaz, IS, Carmen, C, 2015: Helicobacter pylori infection. Mdscape.com/929452-overview.

Nghaimesh, SK, Nazar, SM, NSh, Kader, M A, 2018: Gene sequencing of Blastocystis hominis and its association with $H$. pylori in the development of irritable bowel syndrome. Kirkuk Univer. J. Sci. Stud. (KUJSS), 13, 1:289-303.

Sanad, MM, Darwish, RA, Nasr, ME, EI Gammal, NE, Emara, MW 1996: Giardia lamblia and Chronic Gastritis. J. Egypt. Soc. Parasitol. 26, 2:481-95.

Seid, A, Tamir, Z, Kasanew, B, Senbetay, M, 2018: Co-infection of intestinal parasites and Helicobacter pylori among upper gastrointestinal symptomatic adult patients attending Mekanesalem Hospital, Northeast Ethiopia. BMC Res. Notes 11:144-8

Tandukar, S, Ansari, S, Adhikari, N, et al, 2013: Intestinal parasitosis in school children of Lalitpur District of Nepal. BMC Res. Notes 6, 1: 44-9.

Torres J, Perez, G, Ximenez C, et al, 2003: The association of intestinal parasitosis and $H$. pylori infection in children and adults from a Mexican Community with high prevalence of parasitosis, Helicobacter 8, 3:179-85. 